\title{
Intestinal Injury Associated With Uterine Perforation due to Surgical Abortion in Japan
}

\author{
Shunji Suzuki
}

\section{To the Editor}

Unsafe abortion is one of the leading causes of maternal mortality. Uterine perforation has been observed to be one of main complications of surgical abortion. In 2012, for example, there were 19 uterine perforations in 100,851 induced abortions at less than 12 weeks of pregnancy $(18.0$ per 100,000) in Japan [1]. To date, some reviews and case reports had been reported concerning the presence of intestinal injuries associated with surgical abortion; however, the incidence of the complication has not been well documented [2-4].

We requested 2,544 obstetrical facilities that are members of Japan Association of Obstetricians and Gynecologists to provide information of uterine perforation associated with surgical abortion between 2011 and 2015. A total of 63 cases of uterine perforation were reported during the study period.

Table 1 shows the clinical description and outcomes of the 63 cases of uterine perforation due to surgical abortion. As shown in Table 1, the rate of perforation requiring surgical repair of uterus was at least $84 \%$, while the incidence of intestinal injury requiring surgical repair was at least $56 \%$. In addition, an ostomy was required in three cases of them $(3 / 35 ; 9 \%)$.

In the current observation in Japan, the incidence of intestinal injury in the uterine perforations due to surgical abortion seemed to be high (about 60\%). The incidence of total complications and uterine perforation associated with surgical abortion in Japan has seemed to be lower than that in the Western countries [1]. In Japan, the rate of sharp curettage still remains one of the most frequently used procedures for surgical abortion unlike the Western countries. The intraperitoneal manipulation with placental forceps and/or sharp curettage may be easy to damage the intestinal tract. If uterine perforation is suspected following surgical abortion in Japan, we should not prevent hesitating laparotomy.

\section{References}

1. Sekiguchi A, Ikeda T, Okamura K, Nakai A. Safety of in-

Manuscript accepted for publication January 05, 2017

Department of Obstetrics and Gynecology, Japanese Red Cross Katsushika Maternity Hospital, 5-11-12 Tateishi, Katsushika-ku, Tokyo 124-0012, Japan. Email: czg83542@mopera.ne.jp

doi: https://doi.org/10.14740/gr766w
Table 1. Clinical Description and Outcomes of 63 Cases of Uterine Perforation due to Surgical Abortion

\begin{tabular}{|c|c|c|}
\hline & Number & Percentage \\
\hline Total & 63 & $100 \%$ \\
\hline \multicolumn{3}{|l|}{ Indication for surgery } \\
\hline Artificial abortion & 36 & $57 \%$ \\
\hline Missed/incomplete abortion & 25 & $40 \%$ \\
\hline Unknown & 2 & $3 \%$ \\
\hline \multicolumn{3}{|l|}{ Gestational age at abortion } \\
\hline$<12$ weeks & 45 & $71 \%$ \\
\hline$\geq 12$ weeks & 5 & $8 \%$ \\
\hline Unknown & 13 & $21 \%$ \\
\hline \multicolumn{3}{|l|}{ Additional surgery } \\
\hline Laparotomy & 43 & $68 \%$ \\
\hline Laparoscopic surgery & 10 & $16 \%$ \\
\hline No surgery & 5 & $8 \%$ \\
\hline Unknown & 5 & $8 \%$ \\
\hline \multicolumn{3}{|l|}{ Intestinal injury } \\
\hline Yes & 35 & $56 \%$ \\
\hline No & 18 & $29 \%$ \\
\hline Unknown & 10 & $16 \%$ \\
\hline
\end{tabular}

duced abortions at less than 12 weeks of pregnancy in Japan. Int J Gynaecol Obstet. 2015;129(1):54-57.

2. Sama CB, Aminde LN, Angwafo FF, 3rd. Clandestine abortion causing uterine perforation and bowel infarction in a rural area: a case report and brief review. BMC Res Notes. 2016;9:98.

3. Augustin G, Majerovic M, Luetic T. Uterine perforation as a complication of surgical abortion causing small bowel obstruction: a review. Arch Gynecol Obstet. 2013;288(2):311-323.

4. Coughlin LM, Sparks DA, Chase DM, Smith J. Incarcerated small bowel associated with elective abortion uterine perforation. J Emerg Med. 2013;44(3):e303-306. 